Subscriber access provided by Bibliothèque ÉTS

\title{
Article
}

\section{Wetting of hydrophilic electrospun mats produced by blending SEBS with PEO-PPO-PEO copolymers of different molecular weight}

Rafael Salles Kurusu, and Nicole Raymonde Demarquette

Langmuir, Just Accepted Manuscript • DOI: 10.1021/acs.langmuir.5b04287 • Publication Date (Web): 29 Jan 2016

Downloaded from http://pubs.acs.org on February 1, 2016

\section{Just Accepted}

"Just Accepted" manuscripts have been peer-reviewed and accepted for publication. They are posted online prior to technical editing, formatting for publication and author proofing. The American Chemical Society provides "Just Accepted" as a free service to the research community to expedite the dissemination of scientific material as soon as possible after acceptance. "Just Accepted" manuscripts appear in full in PDF format accompanied by an HTML abstract. "Just Accepted" manuscripts have been fully peer reviewed, but should not be considered the official version of record. They are accessible to all readers and citable by the Digital Object Identifier (DOI®). "Just Accepted" is an optional service offered to authors. Therefore, the "Just Accepted" Web site may not include all articles that will be published in the journal. After a manuscript is technically edited and formatted, it will be removed from the "Just Accepted" Web site and published as an ASAP article. Note that technical editing may introduce minor changes to the manuscript text and/or graphics which could affect content, and all legal disclaimers and ethical guidelines that apply to the journal pertain. ACS cannot be held responsible for errors or consequences arising from the use of information contained in these "Just Accepted" manuscripts.

This document is the Accepted Manuscript version of a Published Work that appeared in final form in Langmuir, copyright (C) American Chemical Society after peer review and technical editing by the publisher.

To access the final edited and published work see http://dx.doi.org/10.1021/acs.langmuir.5b04287. 


\title{
Wetting of hydrophilic electrospun mats produced
}

\section{by blending SEBS with PEO-PPO-PEO copolymers of different molecular weight}

\author{
Rafael S. Kurusu, Nicole R. Demarquette \\ Mechanical Engineering Department, École de technologie supérieure - ÉTS, \\ 1100 Notre-Dame Street West, Montréal, Québec - Canada H3C 1K3
}

\begin{abstract}
The interaction of electrospun mats with water is critical for many possible applications, and the water contact angle on the surface is the parameter usually measured to characterize wetting. Although useful for hydrophobic surfaces, this approach is limited for hydrophilic mats, where wicking has also to be considered. In this case, it is still unclear how the fiber surface chemical composition and morphology will affect the wetting behavior of electrospun mats. In this work, wetting was studied with different hydrophilic membranes produced by blending thermoplastic elastomer SEBS with amphiphilic PEO-PPO-PEO molecules. Three different types of PEO-PPO-PEO, with different molar masses, PEO content and physical form were used. The effect of these differences on the wetting behavior of the electrospun mats was evaluated by contact angle goniometry, wicking measurements and
\end{abstract}


different imaging techniques. X-ray photoelectron spectroscopy was used to characterize the surface chemical composition. The smaller molecules quickly saturated the surface at low concentrations, making the mats hydrophilic. The sheath of PEO-PPO-PEO also resulted in fast absorption of water, when comparing the saturated and non-saturated surfaces. Longer PEO chain-ends seemed to hinder complete segregation and also led to a higher activation time when in contact with water. Liquid PEO-PPO-PEO was easily leached by water.

\section{INTRODUCTION}

High surface area is one of the main features of electrospun mats and therefore understanding and controlling their surface properties is critical. Water wetting, for example, will help defining the performance of mats for several possible applications where there is interaction with aqueous solutions, such as separation and filtration membranes or scaffolds for tissue engineering ${ }^{1,2,3}$.

Electrospun mats are generally classified as hydrophobic or hydrophilic. In the case of many polymers ${ }^{4,5,6,7}$, the mats produced by electrospinning are hydrophobic and need to undergo a post-treatment in order to present hydrophilicity. This can be achieved by hydrolysis ${ }^{4,5}$, plasma $^{8}$, immersion precipitation ${ }^{9}$, etc., but this adds time and cost. Another approach is to use polymer blending to incorporate hydrophilic ${ }^{10}$ or amphiphilic ${ }^{11,12}$ polymers in the hydrophobic matrix to alter the surface properties of the fibers. Previously ${ }^{13}$, we have shown that mats of elastomeric poly(styrene)- $b$-poly(ethylene-butylene)- $b$-poly(styrene) (SEBS) could be hydrophilized by blending it with amphiphilic poly(ethylene oxide)- $b$-poly(propylene oxide)- $b$-poly(ethylene oxide) (PEO-PPO-PEO). Not only the chemical composition but also the blend morphology was important to produce a homogeneously hydrophilic mat. The low surface energy PPO midblock tends to segregate to the surface and drag the hydrophilic PEO groups. When in contact with an 
aqueous medium, the hydrophilic PEO segments will extend and the surface will become hydrophilic ${ }^{14}$. There exist other examples in literature where PEO-PPO-PEO polymers have been successfully used to modify the wettability of the electrospun mats ${ }^{11,12}$, but to our knowledge the characterization of wetting was based only in static contact angle measurements.

In the hydrophobic case, electrospun mats can be seen as a rough surface, and many papers in the literature have discussed the reasons and definitions for hydrophobicity based on contact angle measurements and wetting theories ${ }^{15,16}$. In the hydrophilic case, however, electrospun mats cannot be seen only as a rough surface, but also as a porous material subject to absorption by capillary action (wicking). So to better understand the wetting behavior of hydrophilic electrospun mats, not only contact angle but also wicking measurements have to be analyzed. The latter have been used to determine the contact angle of electrospun mats indirectly ${ }^{5}$, or to compare the wicking rate of spunbond and electrospun fibers ${ }^{7}$, mats of the same polymer with different fiber diameter ${ }^{6}$ or mats containing two types of fibers independently co-electrospun ${ }^{4}$. Another way used to characterize the dynamics of wetting is the observation of the spontaneous spreading or impact of droplets ${ }^{17,} 18$, which can also be important for applications in humid conditions or related to the deposition of aqueous fluids. However, it is still unclear how the fiber surface chemistry and morphology will affect wetting of electrospun mats.

Since there are many different grades of PEO-PPO-PEO copolymers commercially available, combining hydrophilization by blending with different types of PEO-PPO-PEO and analyzing contact angle, wicking rate, spreading and impact of water on the mats can give new information about the role of fiber surface composition and morphology on the wetting behavior of electrospun mats. In this work, SEBS/PEO-PPO-PEO mats were produced by electrospinning with three types of PEO-PPO-PEO molecules having different molar masses, PEO content and 
physical form (one is a solid polymer, the other a paste-like material and the last one a viscous liquid). The effect of these differences on the wetting behavior of the mats was evaluated by contact angle, wicking measurements and imaging techniques. Surface chemical composition and both mat and fiber morphology were also characterized.

\section{EXPERIMENTAL}

Linear triblock copolymer SEBS (G1652) with $79000 \mathrm{~g} / \mathrm{mol}$ of average molecular weight and $30 \mathrm{wt} \%$ of styrene blocks was kindly supplied by Kraton. PEO-PPO-PEO copolymers (Pluronic $^{\circledR}$ ) were purchased from Sigma Aldrich. Chloroform and toluene were purchased from Fisher Scientific. Three types of PEO-PPO-PEO copolymers were used: Pluronic ${ }^{\circledR}$ F127, Pluronic ${ }^{\circledR}$ P123 and Pluronic ${ }^{\circledR}$ L61, each with different molecular weight and PEO content. The main characteristics are presented in Table 1 with a visual comparison using an arbitrary scale of the difference in length and PEO content in each polymer with the respective number of EO and PO repeat units.

Table 1 - Main features of the PEO-PPO-PEO copolymers used in the present study.

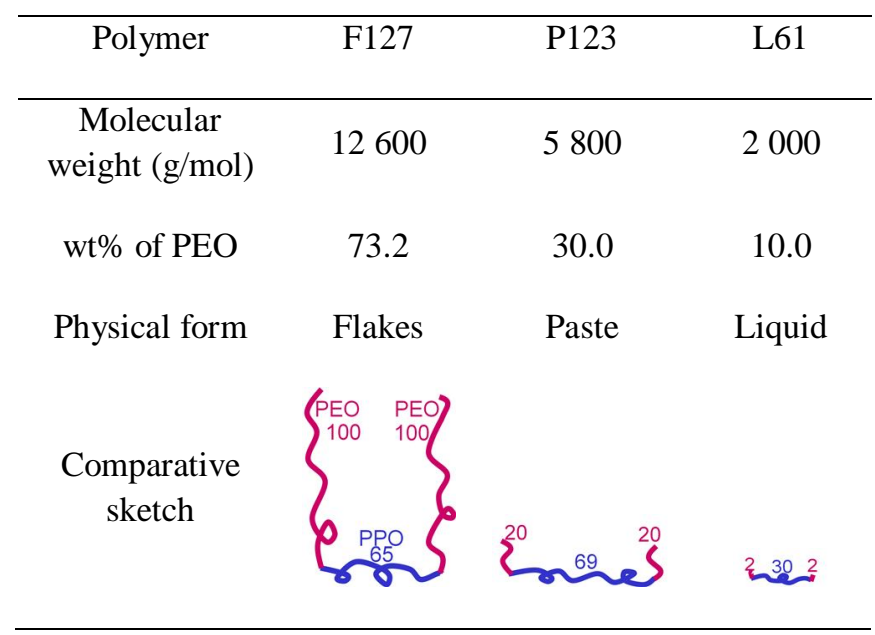


The polymers were weighed and mixed with chloroform and toluene (80/20 wt $\%$ ) using a magnetic stirrer for 15 minutes until a homogeneous solution was obtained. The final polymer concentration for all solutions was $15 \mathrm{wt} \%$. Four compositions of SEBS/PEO-PPO-PEO with 5, 10, 15 and 20 wt\% of each PEO-PPO-PEO were prepared and named as F127_x, P123_x and L61_x, where $x$ is the wt\% of PEO-PPO-PEO.

Electrospinning was performed with $10 \mathrm{ml}$ syringes, $21 \mathrm{G}$ needles, voltage of $15 \mathrm{kV}$, distance to collector of $15 \mathrm{~cm}$ and flow rate of $2 \mathrm{~mL} / \mathrm{h}$. All the tests were performed at room temperature and $30 \%$ of relative humidity.

Water contact angle measurements were performed with a VCA Optima (AST products, Inc.) and Milli- $\mathrm{Q}^{\circledR}$ ultrapure water. Mat strips were attached to glass slides to maintain a horizontal surface. Each blend was tested five times in different regions of the mats.

For the wicking measurements, ultrapure water was dyed with methylene blue and poured in a beaker. Mat strips with $20 \mathrm{~mm}$ of height, $10 \mathrm{~mm}$ of width and 150-200 $\mu \mathrm{m}$ of thickness were attached to a polyethylene tab containing a millimetric scale. The tab was lowered until the solution touched the mat and the water started to rise by capillary action. All the process was recorded with a Canon T4i at thirty frames per second. The time to reach each millimeter in the scale was then plotted in a height vs. time graph. Three samples of each composition were tested.

Optical microscopy was performed with an Olympus BX51 with magnification up to $1000 \times$ to observe the fiber morphology and leaching. Scanning electron microscopy (SEM) was used to observe both the mat morphology (fiber diameter and shape) and fiber surface morphology. The experiments were performed with a $\mathrm{S} 3600 \mathrm{~N}$ microscope (Hitachi) at $5 \mathrm{kV}$ in secondary electrons mode. The samples were previously coated with platinum using a Q150T S (Quorum Technologies) sputter coater. High-speed images of wetting were obtained using a Fastcam SA1 
Camera (Photron Ltd, Tokyo, Japan) working at 500 to 2000 frames per second depending on the absorption velocity of each sample. This technique was used to analyze the dynamics of spreading and impact of water drops on the mat surfaces. All images were analyzed using ImageJ and the plugin Diameter ${ }^{19}$ for measurements.

The surface chemical composition of the samples was measured by X-ray Photoelectron Spectroscopy (XPS) using an ESCALAB 3 MKII with a Mg K $\alpha$ source and 216W (12 kV, 18 $\mathrm{mA}$ ) of power. An area of $2 \mathrm{~mm} \times 3 \mathrm{~mm}$ was analyzed for each sample, with a depth of analysis of $50-100 \AA$.

\section{RESULTS AND DISCUSSION}

Figure 1 shows the water contact angle results for each blend as a function of PEO-PPO-PEO bulk content for the three types of PEO-PPO-PEO (F127, P123 and L61). Pure SEBS mats were hydrophobic with contact angle of $139 \pm 2^{\circ}$. For the blends containing F127, the hydrophilization (absorption resulting in contact angle of $0^{\circ}$ ) was achieved at $15 \mathrm{wt} \%$ of PEO-PPO-PEO, but only the composition with $20 \mathrm{wt} \%$ presented a homogeneous hydrophilicity in all regions of the mat. The addition of 5 wt\% P123 or L61 was enough to hydrophilize the mats. Blends with only 1 wt $\%$ of P123 and L61 were later prepared, producing hydrophobic mats with contact angle closer to pure $\operatorname{SEBS}\left(\approx 140^{\circ}\right)$. 


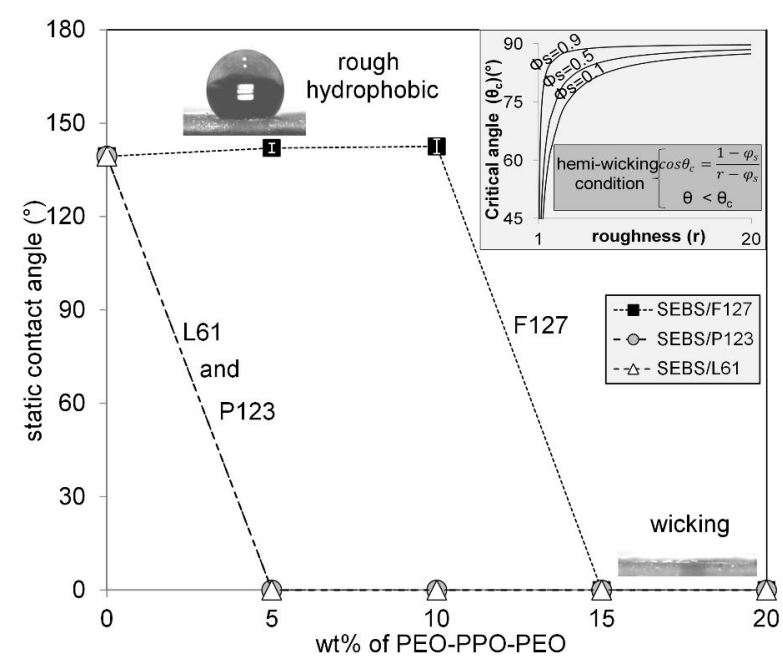

Figure 1 - Water contact angle results for all electrospun mats as a function of PEO-PPO-PEO content. The insert is a plot of the hemi-wicking condition ${ }^{20}$, the critical contact angle $\theta_{c}$ as a function of roughness $r$ for different values of solid/liquid interface fraction $\left(\varphi_{S}\right)$.

The condition for wicking in a perfect capillary is that the surface energy between the solid and the liquid $\left(\gamma_{S L}\right)$ must be smaller than the surface energy between the solid and the air/vapour $\left(\gamma_{S V}\right)$. Using the equilibrium contact angle $\theta_{E}$ of the Young's equation $\left(\gamma_{S V}-\gamma_{S L}=\gamma_{L V} \cos \theta_{E}\right)$, which describes the balance of energies for a drop of liquid deposited in a perfectly flat surface, the condition for wicking may be written as ${ }^{21} \theta_{E}<90^{\circ}$ that gives $\gamma_{S V}-\gamma_{S L}>0$.

Electrospun mats can be considered as non-perfect porous structures in which the solid/vapour interface will not be ideally replaced by a solid/liquid interface, leaving some dry islands. The condition for wicking or hemi-wicking can be described $\operatorname{as}^{20}$ :

$\theta_{E}<\theta_{c}$ and $\cos \theta_{c}=\frac{1-\varphi_{s}}{r-\varphi_{s}}$

where $r$ is the roughness (ratio of the real area to the projected area), $\varphi_{s}$ is the fraction of the solid/liquid interface below the drop, $\theta_{E}$ is again the equilibrium contact angle on an ideal flat surface with the same chemical composition of the rough surface and $\theta_{c}$ is the critical contact 
angle that will define the start of the imbibition ${ }^{20}$. For a perfect porous material $(r \rightarrow \infty$ and therefore $\cos \theta_{c} \rightarrow 0$ ), wicking will occur again for $\theta_{E}<90^{\circ}$ and, if this condition is fulfilled, the final apparent contact angle will be $0^{\circ}$. Considering that electrospun mats are porous materials with high values of roughness, the condition for imbibition is easily achieved, and for any value of $\varphi_{s}, \theta_{c}$ tends to be close to $90^{\circ}$, as shown in the insert in Figure 1 . This explains the recurrent switch (ON/OFF) mechanism found for the contact angle of electrospun mats, from hydrophobic or superhydrophobic rough surfaces with high contact angle values to superhydrophilic absorbing porous structures with contact angle zero ${ }^{10,12,22,23,24}$.

Mats that present values of contact angle smaller than $90^{\circ}$ but higher than $0^{\circ}$ can be a result of: non-uniform chemical composition, with hydrophobic regions unevenly mixed with hydrophilic regions; small mat thickness with insufficient pore volume to absorb the droplet; measurement at different times, as some mats present a slow wicking rate until the contact angle reaches zero. The contact angle right after the droplet deposition may be different from zero and then reach zero after a time interval ${ }^{12}$. In the case of this work, the absorption occurred rapidly after the drop deposition.

The contact angle measurement was useful to determine the effectiveness of the hydrophilization treatment chosen, i.e., blending with PEO-PPO-PEO molecules, but it did not allow a comparison between the different hydrophilic compositions. To investigate the dynamics of spreading and imbibition from the moment the drop touched the mat until it was completely absorbed, high-speed imaging was used (Figure 2). Four compositions were chosen for clarity and because they summarize the main trends observed. The evolution of the contact angle $\theta$ of the droplet on the surface was observed as a function of time (Figure 2a). Upon contact, all mats presented contact angles around $140^{\circ}$, which is similar to the values obtained for pure SEBS and 


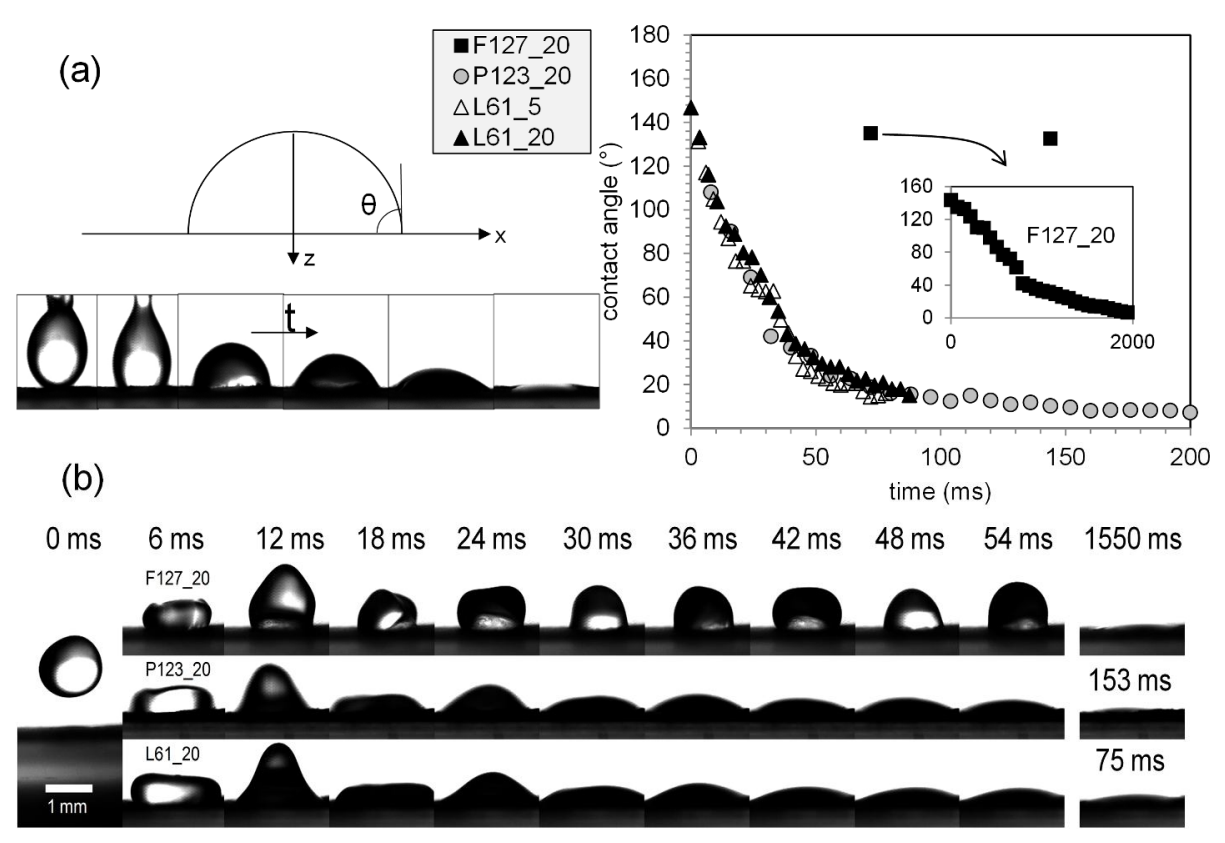

Figure 2 - (a) spreading and imbibition experiments methodology and results for the contact angle $\theta$ as a function of time; (b) drop impact images showing the last frame before impact as the first image and the total time for absorption as the final image for F127_20, P123_20 and L61_20 (top to bottom). 
The differences in drop absorption between F127_20, P123_20 and L61_20 were also observed in drop impact experiments (Figure 2b). For the F127_20 mat, there was no apparent change in volume and contact angle in the early stages after the impact, and droplet moved up and down for a longer time without bouncing. In the case of P123_20 and L61_20, the droplet adhered and moved on the surfaces while it was rapidly absorbed. As concluded by the spreading experiments, there was a drastic difference between the behavior of F127_20 and the P123_20 and L61_20. Also, the impact reduced the final absorption time by about $20 \%$. The pictures presented in Figure $2 \mathrm{~b}$ also show that in all cases the drop adhered to the surface and no splashing was observed.

One way to predict the impact behavior of a liquid drop on a surface is to calculate the dimensionless Weber number $\left(W e=\rho r v^{2} / \gamma\right)$, where $\rho$ is the liquid density, $r$ the drop radius, $v$ its impact velocity and $\gamma$ the surface tension. A rough evaluation of the Weber number for the present work ( $\rho=1000 \mathrm{~kg} \cdot \mathrm{m}^{-3}, r=650 \mu \mathrm{m}, \mathrm{v}=0.3 \mathrm{~m} \cdot \mathrm{s}^{-1}$ and $\gamma=72 \mathrm{mN} \cdot \mathrm{m}^{-1}$ ) leads to $W e=8.2$, which is much lower than the splashing thresholds usually reported ${ }^{25,26,27}$, even considering that the roughness can reduce this limit ${ }^{28}$, explaining therefore the absence of splashing in our work. Furthermore, hydrophilic surfaces cause a much stronger viscous dissipation near the moving contact line that slows down the droplet spreading, in contrast to hydrophobic surfaces ${ }^{26}$, which can also contribute to avoid splashing. However, it is worth noting that a small increase in the drop velocity drastically changes the impact behavior, and that even hydrophobic electrospun membranes can be penetrated by water if the velocity is high enough ${ }^{29,30}$. Lembach et. al ${ }^{30}$ also performed drop impact experiments on electrospun mats produced with a partially wettable polymer, and defined a splashing threshold for these mats. To reach this threshold with the mats 
used in the present work, a velocity of $2.7 \mathrm{~m} / \mathrm{s}$ would be necessary (much higher than the one used in the present work).

Wicking experiments with mat strips were performed to evaluate another aspect of the wetting behavior $^{31}$ of electrospun materials. The results are presented in Figure $3 \mathrm{a}$ for the hydrophilic compositions from the moment the dyed water touched the mat until it reached the sample height of $20 \mathrm{~mm}$, as shown by the pictures in Figure 3a. Although ultimately hydrophilic in terms of contact angle, the strips of the composition with 15 wt $\%$ of F127 presented heterogeneous water rise with time so that the results are not shown here. The dyed water had a preference for the more hydrophilic regions, which were randomly distributed in the mats. Controlling the exact location of hydrophobic and hydrophilic regions could lead to a tailored wicking behavior that could be interesting for applications involving fluid transport.

The wicking rate was clearly smaller for the mat with $20 \mathrm{wt} \%$ of F127, and the time to reach the maximum height was about 17 seconds. All the mats with P123 quickly absorbed water with a total time between 5 and 8 seconds. The wicking rate for the mats with L61 was even higher with total time between 4 and 6 seconds to reach the maximum height. 

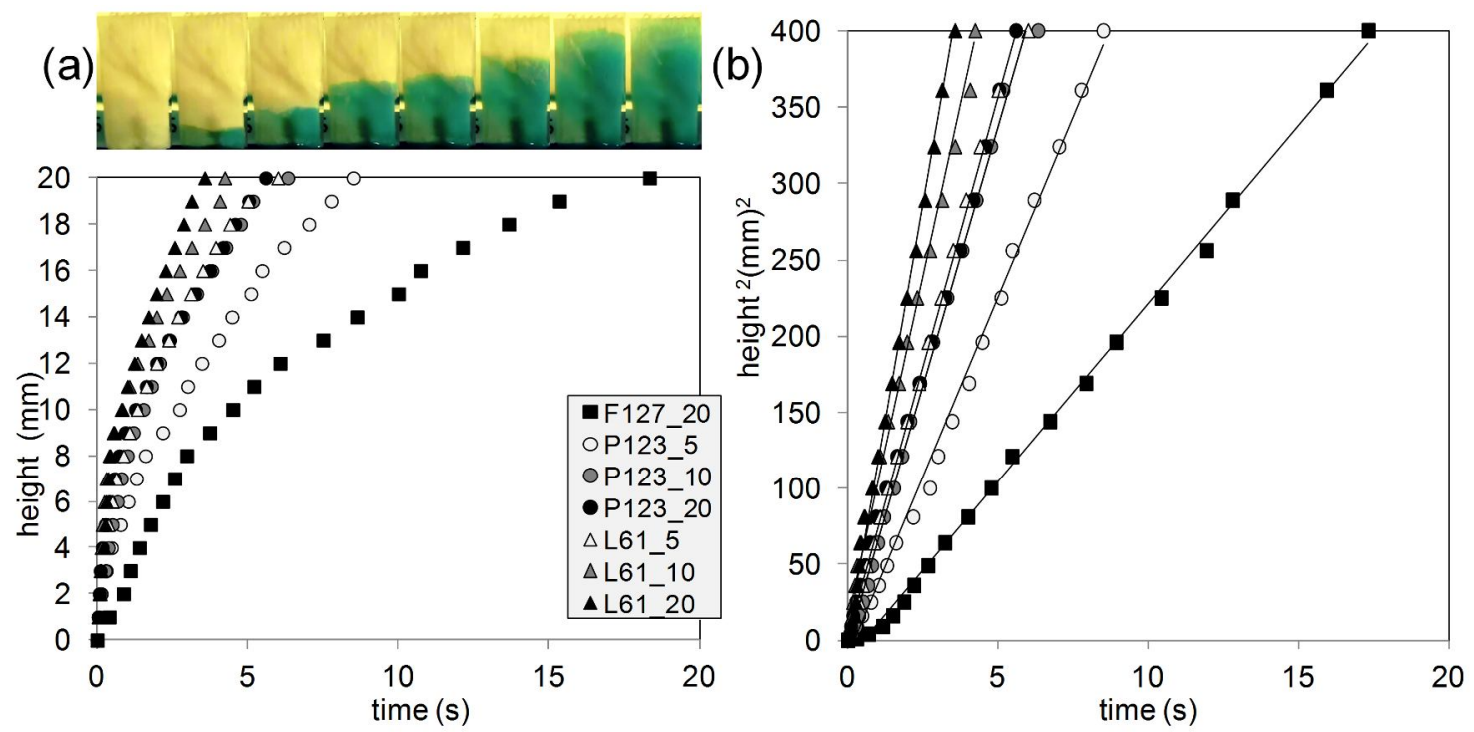

(c)

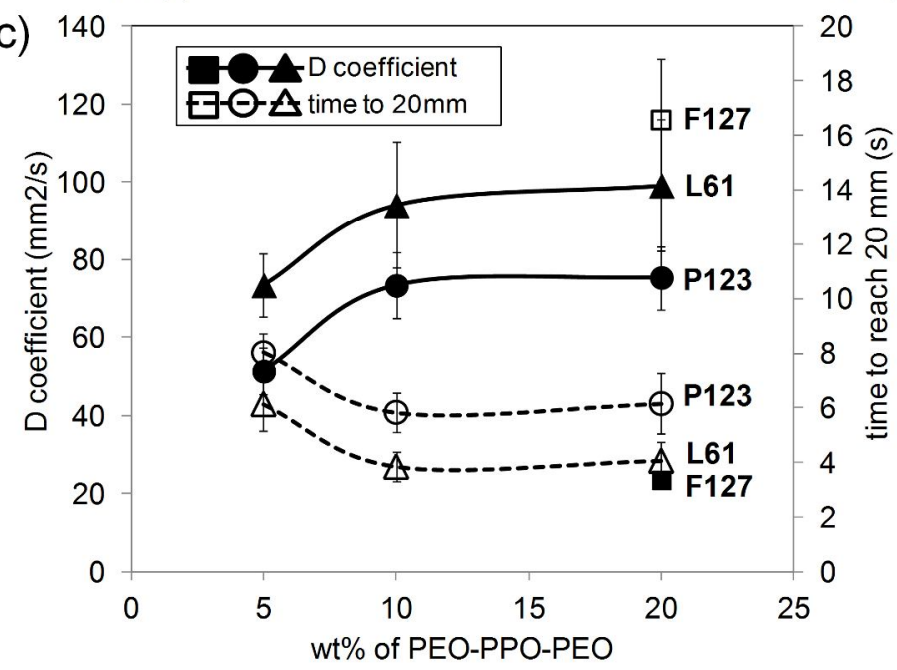

Figure 3 - Results for the wicking measurements: (a) example of the experiments pictures and the results for height as a function of time; (b) the square of height $\left(h^{2}\right)$ versus time; (c) Diffusion coefficient $D$ and total time to reach the maximum height as a function of PEO-PPO-PEO content.

Porous materials like electrospun mats can exhibit classical wicking dynamics analogous to what was described by Washburn ${ }^{32}$ considering a porous structure as a series of $n$ cylindrical 
capillaries with an equivalent radius of the capillary structure $r$. Neglecting the hydrostatic pressure, the relation between the height $h$ and time $t$ can be described as ${ }^{33}$ :

$$
h^{2}=\left(\frac{r \cdot \cos \theta_{E}}{2}\right) \cdot\left(\frac{\gamma}{\eta}\right) \cdot t
$$

where $\gamma$ and $\eta$ correspond to the surface tension and viscosity of the liquid. The rise of liquid in a capillary then takes the form:

$$
h^{2}=D \cdot t
$$

where $D$ is a diffusion coefficient based on fluid properties and capillary geometry, and the square of the height varies linearly with time. Figure $3 \mathrm{~b}$ shows that the equation fitted well to the wicking behavior of electrospun mats considering the whole experiment, as previously reported ${ }^{6}$, ${ }^{7}$. The differences in wicking rate described before are easier to observe.

Figure $3 \mathrm{c}$ presents the $D$ coefficient and time to reach the maximum height as a function of PEO-PPO-PEO content for all the compositions and samples tested. The time to reach the maximum height of $20 \mathrm{~mm}$, a parameter used in many wicking standards, decreased with higher PEO-PPO-PEO content, but reached a plateau around $10 \mathrm{wt} \%$. The D coefficient followed the inverse trend, increasing with PEO-PPO-PEO content, but also stabilizing after $10 \mathrm{wt} \%$.

Since $D=\left(r \cdot \cos \theta_{E} / 2\right) \cdot(\gamma / \eta)$ and only water was used in the experiments (constant $\gamma$ and $\left.\eta\right)$, any difference in the wetting behavior comes from differences on the pore structure or the surface chemical composition.

The main structure parameters that will affect wicking in a simplified electrospun mat (Insert in Figure 4b) are the fiber diameter $d$ and the distance between fibers $f$, which will influence pore (capillary) size. SEM images for some of the samples are presented in Figure 4a, showing that all compositions produced homogeneous fibers with the exception of P123_20, which presented fibers with varying diameter, and L61_20, which presented broken fibers. Fiber diameter 
decreased drastically with the incorporation of $5 \mathrm{wt} \%$ of all three types of PEO-PPO-PEO molecules, and remained stable until the maximum concentration of $20 \mathrm{wt} \%$ (Figure $4 \mathrm{~b}$ ) The only exceptions are again P123_20 and L61 20, which presented an increase in the average diameter (Figure 4b). The higher amount of PEO-PPO-PEO started to disrupt the electrospinning process in these two cases. Image analysis was performed to calculate the distance between fibers and the pore size of the mats, but the data (not presented here) revealed, as expected, a great variation since the mats are composed of randomly oriented fibers. However, it is known that mats containing fibers of smaller diameter have smaller pores ${ }^{34}$, so that one could expect smaller pores for the blends containing F127 and therefore smaller capillaries that would increase the wicking rate, but that was not observed. The total porosity value taken from immersion experiments in ethanol revealed similar values for all mats (around 75\%). Therefore, based on this simple analysis, there is no apparent correlation between geometry and the wetting behavior of the mats.
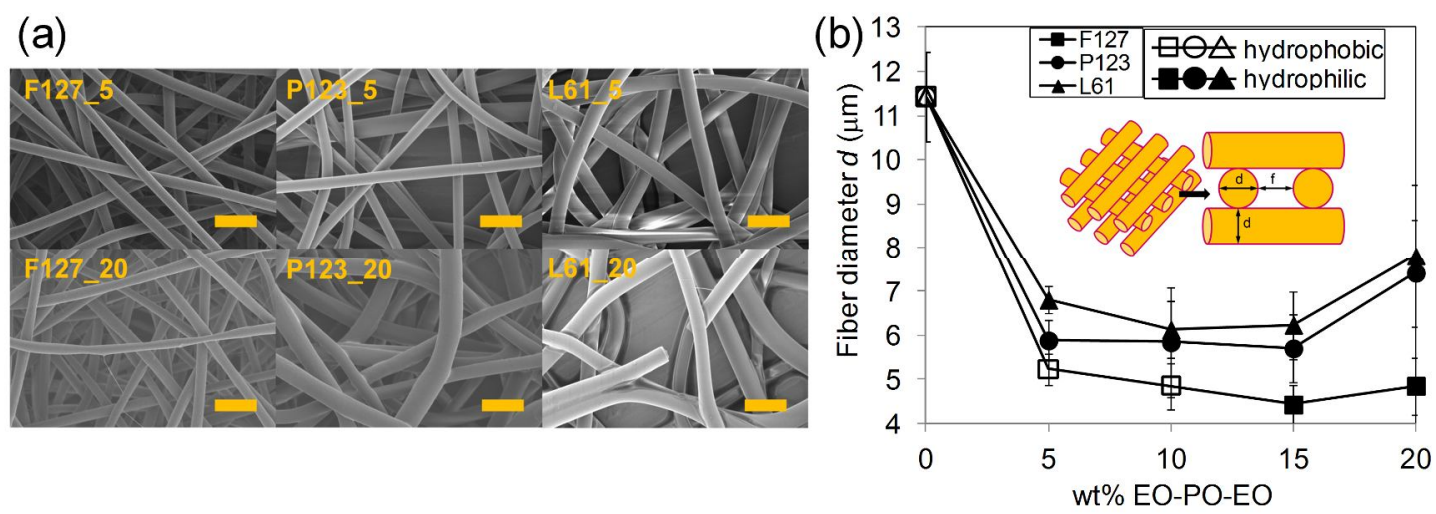

Figure 4 - (a) SEM micrographs of the samples containing 5 and $20 \mathrm{wt} \%$ of PEO-PPO-PEO (scale bar $=20 \mu \mathrm{m})$ and $(\mathrm{b})$ the results of fiber diameter as a function of PEO-PPO-PEO content for all samples. 
The chemical composition at the very top surface of the mats, measured by XPS, is presented in Figure 5. Since only the PEO-PPO-PEO molecules have oxygen, the atomic percentage of this element can tell whether the surface is enriched with this polymer or not. Figure 5a shows the XPS survey spectra for pure SEBS, the three blends containing $20 \mathrm{wt} \%$ of PEO-PPO-PEO and a film of pure PEO-PPO-PEO (P123). The small oxygen peak in the spectrum of pure SEBS, combined with a small silicon peak, appeared possibly due to a small amount of silicone oils that can be found in some commercial polymers. The spectra for P123_20, L61_20 and pure PEOPPO-PEO (P123) presented similar proportion between carbon and oxygen peaks, although the sample for pure PEO-PPO-PEO was a film, since it is not electrospinnable. The curves in Figure $5 \mathrm{~b}$ show the atomic percentage of oxygen for each composition. From bottom to top, the straight lines without markers show the theoretical amount of oxygen expected according to the bulk compositions and the theoretical amount of oxygen in pure L61, P123 and F127, respectively. All compositions presented surface enrichment with PEO-PPO-PEO, which confirms that there was segregation of these molecules. For the blends with F127 there was a gradual increase in the amount of oxygen according to the composition. Blends with P123 showed an instant high amount of oxygen at $5 \mathrm{wt} \%$ of P123, similar to the blend with $20 \mathrm{wt} \%$ of F127. From 10 until 20 wt\% of P123, the surface is practically saturated (91 to $100 \mathrm{wt} \%$ ) with PEO-PPO-PEO molecules. When L61 was use as the second phase, all compositions tested presented completely coverage with the amphiphilic molecule. 

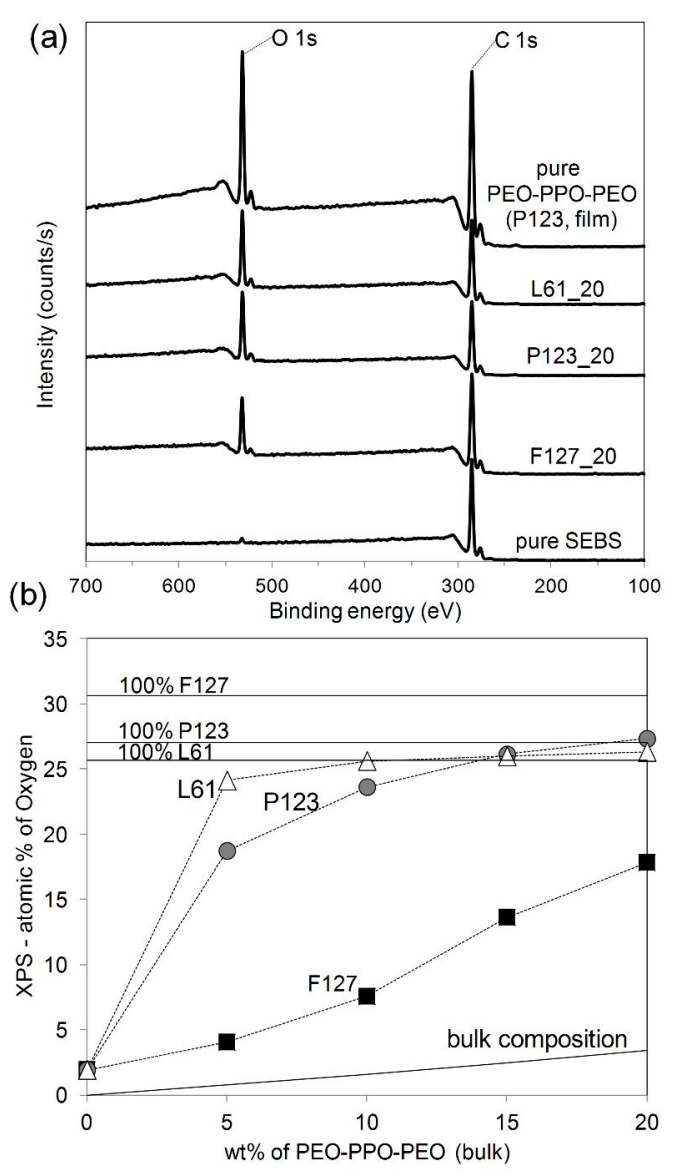

Figure 5 - (a) X-ray photoelectron spectroscopy (XPS) survey spectra for pure SEBS, F127_20, P123_20, L61_20 and pure PEO-PPO-PEO; (b) XPS results of the atomic percentage of oxygen as a function of blend bulk composition. The straight lines are theoretical values based on the chemical structure of each molecule.

The results show that the amount of PEO-PPO-PEO needed to achieve surface coverage and the consequent changes in surface properties is smaller for the molecules with lower molecular weight. Surface hydrophilization depends on the extension of PEO chain ends of each molecule when the surface is in contact with water. The length of PEO chain ends of the three PEO-PPOPEO molecules chosen for this study varies greatly: F127 ( $\left.\mathrm{PEO}_{100}-\mathrm{PPO}_{65}-\mathrm{PEO}_{100}\right)$ has 
approximately $100 \mathrm{EO}$ units in each side of the molecule, while P123 $\left(\mathrm{PEO}_{20}-\mathrm{PPO}_{69}-\mathrm{PEO}_{20}\right)$ and L61 $\left(\mathrm{PEO}_{2}-\mathrm{PPO}_{30}-\mathrm{PEO}_{2}\right)$ have in average 20 and 2 units of $\mathrm{EO}$ in each PEO block, respectively $^{35}$. The blends F127_20 and P123_5 have similar chemical compositions, but remarkably different wicking behavior, which indicate that the shorter PEO chains are activated faster in P123. An analogous behavior is observed when comparing the blends with saturated surfaces. The compositions with L61 molecules showed a faster wicking than the membranes containing P123 molecules (Figure 3). A plot of the time to reach the maximum height in the wicking experiments as a function of PEO length in each chain end (Figure 6) shows that wicking rate increased with decreasing PEO length. Furthermore, for each molecule of F127 with two PEO chain-ends, there are approximately two times more P123 molecules and six times more L61 molecules, considering the same mass of polymer used.

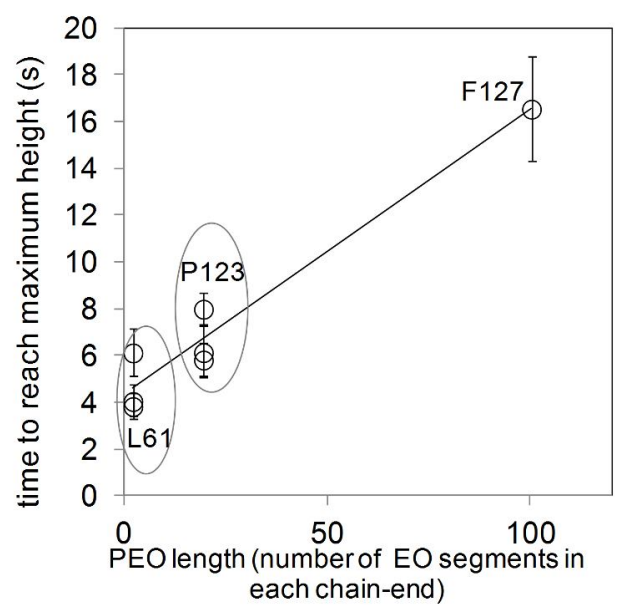

Figure 6 - Wicking results as a function of the number of EO segments in each side of the PEOPPO-PEO molecules. 
Besides the idea of a longer time to extend and hydrophilize the surface, another possible explanation is that the longer PEO chain-ends, like in F127, hindered the segregation of the molecule. Both arguments are plausible when comparing F127_20 and P123_5, blends with similar surface chemical composition and PPO-block length. The wicking rate was higher for P123_5, indicating faster activation, but the amount of PEO-PPO-PEO (bulk composition) in this blend is much smaller than in F127_20, indicating faster segregation.

Results above showed that SEBS electrospun fibers blended with PEO-PPO-PEO molecules presented graded morphology with a PEO-PPO-PEO-rich surface, resulting in mat hydrophilization. Smaller PEO-PPO-PEO molecules seem to be more effective to generate faster water absorption even though the order of molecular hydrophilicity (proportion of PEO) is F127>P123>L61.

Once the surface is saturated, the compositions with higher concentrations will tend to have a thicker surface layer of PEO-PPO-PEO, which can contribute to fast interaction with water. But this thicker layer can also be more easily removed or leached by water. In the particular case of SEBS/L61 fibers, a liquid residue was observed whenever the mats were placed on a glass slide. Leaching of L61_20 fibers by water was then observed by optical microscopy (Figure 7a). When the flow of water passed (arrow in Figure 7a), L61 molecules were removed from the fibers surface and formed bubbles in fractions of a second. The wetting behavior of the SEBS/L61 blends with higher concentrations of L61 was mainly a result of a liquid surface exuded from the SEBS matrix. The SEM image of the L61_20 fibers (Figure 7b) also revealed a residue on the substrate after fiber deposition, in addition to broken fibers. Higher concentrations of the smaller molecules of L61 reduced the stability of the jet during electrospinning, leading to fiber breakage in some points due to the electrical forces and bending instabilities. 


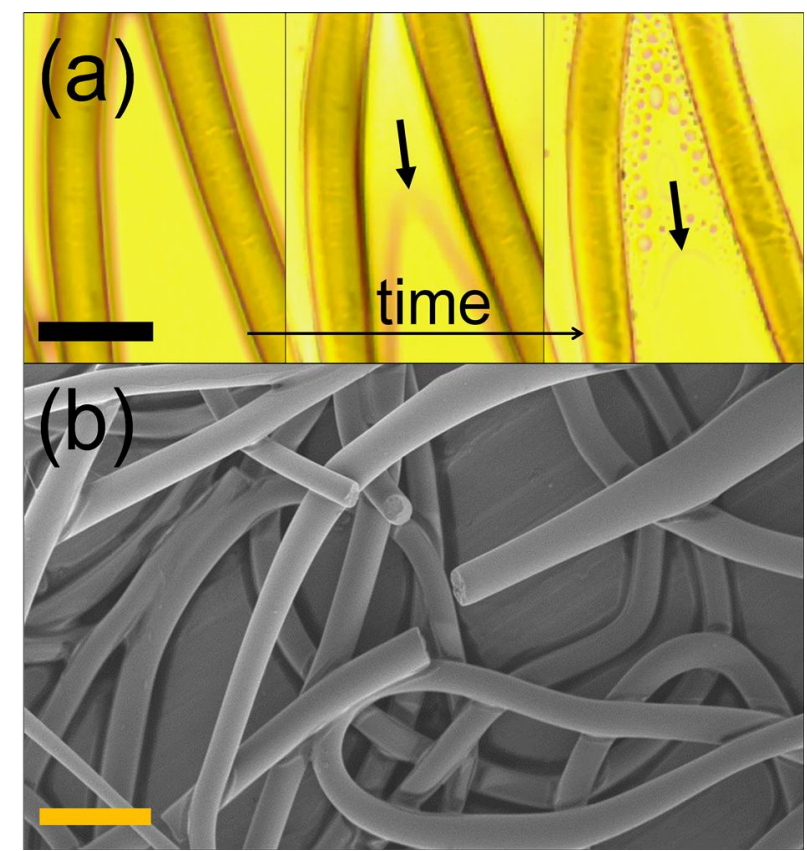

Figure 7 - L61_20 fibers: (a) L61 leaching observed by optical microscopy, in which the arrows indicate the water front advancing direction (scale bar $=10 \mu \mathrm{m}$ ); (b) SEM image of the same composition showing broken fibers (scale bar $=30 \mu \mathrm{m}$ ).

Leaching could not be observed for the other compositions with only optical microscopy and static contact angle measurements. Leaching is a problem for applications that demand long-term hydrophilicity, but it can be interesting for other applications where the release of molecules is targeted. A more systematic and detailed study is needed to understand how to control a specific leaching behavior of PEO-PPO-PEO molecules for a given application.

\section{CONCLUSIONS}


Electrospun SEBS fibers were successfully hydrophilized by solution blending with amphiphilic PEO-PPO-PEO molecules. During electrospinning and until solvent evaporation these molecules segregated to the surface and completely altered the wetting behavior of the mats. This was confirmed by the chemical composition at the very top surface.

Although superhydrophilic considering only contact angle measurements, a drastic difference in absorption time was noticed. Wicking tests quantified this difference revealing that the PEOPPO-PEO molecules with smaller molecular weight were more effective, enabling hydrophilization with smaller amount of material incorporated in the SEBS matrix. Moreover, smaller PEO chain-ends seemed to respond more rapidly when in contact with water, resulting in faster wicking. High-speed imaging also reinforced the results.

Liquid PEO-PPO-PEO (L61) is clearly leached from the fibers surface when in contact with water, while the other types of PEO-PPO-PEO molecules (P123 and F127) seemed to produce more robust hydrophilization.

\section{ACKNOWLEDGMENTS}

The authors wish to thank the Natural Sciences and Engineering Research Council of Canada (NSERC), Fond de recherche du Québec (FRQ) and École de Technologie Supérieure (ÉTS) for financial support and Navid Sharifi and Professor Ali Dolatabadi from Concordia University for the help with high-speed imaging.

\section{REFERENCES}


1. Wu, J.; Wang, N.; Zhao, Y.; Jiang, L. Electrospinning of multilevel structured functional micro-/nanofibers and their applications. Journal of Materials Chemistry A 2013, 1 (25), 72907305.

2. Xue, Z.; Cao, Y.; Liu, N.; Feng, L.; Jiang, L. Special wettable materials for oil/water separation. Journal of Materials Chemistry A 2014, 2 (8), 2445-2460.

3. Hutmacher, D. W. Scaffolds in tissue engineering bone and cartilage. Biomaterials 2000, 21 (24), 2529-2543.

4. Khatri, Z.; Wei, K.; Kim, B.-S.; Kim, I.-S. Effect of deacetylation on wicking behavior of co-electrospun cellulose acetate/polyvinyl alcohol nanofibers blend. Carbohydrate Polymers 2012, 87 (3), 2183-2188.

5. Liu, H.; Hsieh, Y.-L. Ultrafine fibrous cellulose membranes from electrospinning of cellulose acetate. Journal of Polymer Science Part B: Polymer Physics 2002, 40 (18), 21192129.

6. De Schoenmaker, B.; Van der Schueren, L.; De Vrieze, S.; Westbroek, P.; De Clerck, K. Wicking properties of various polyamide nanofibrous structures with an optimized method. $J$ Appl Polym Sci 2011, 120 (1), 305-310.

7. Hwa Hong, K.; Jin Kang, T. Hydraulic permeabilities of PET and nylon 6 electrospun fiber webs. J Appl Polym Sci 2006, 100 (1), 167-177.

8. Savoji, H.; Lerouge, S.; Ajji, A.; Wertheimer, M. R. Plasma-Etching for Controlled Modification of Structural and Mechanical Properties of Electrospun PET Scaffolds. Plasma Processes and Polymers 2015, 12 (4), 314-327.

9. Cho, W. J.; Kim, J. H.; Oh, S. H.; Nam, H. H.; Kim, J. M.; Lee, J. H. Hydrophilized polycaprolactone nanofiber mesh-embedded poly(glycolic-co-lactic acid) membrane for effective guided bone regeneration. Journal of Biomedical Materials Research Part A 2009, $91 \mathrm{~A}$ (2), 400-407.

10. Li, G.; Zhao, Y.; Lv, M.; Shi, Y.; Cao, D. Super hydrophilic poly(ethylene terephthalate) (PET)/poly(vinyl alcohol) (PVA) composite fibrous mats with improved mechanical properties prepared via electrospinning process. Colloids and Surfaces A: Physicochemical and Engineering Aspects 2013, 436 (0), 417-424.

11. Liu, N.-h.; Pan, J.-f.; Miao, Y.-E.; Liu, T.-X.; Xu, F.; Sun, H. Electrospinning of poly ( $\varepsilon-$ caprolactone-co-lactide)/Pluronic blended scaffolds for skin tissue engineering. Journal of Materials Science 2014, 49 (20), 7253-7262.

12. Vasita, R.; Mani, G.; Agrawal, C. M.; Katti, D. S. Surface hydrophilization of electrospun PLGA micro-/nano-fibers by blending with Pluronic ${ }^{\circledR}$ F-108. Polymer 2010, 51 (16), 3706-3714.

13. Kurusu, R. S.; Demarquette, N. R. Blending and Morphology Control To Turn Hydrophobic SEBS Electrospun Mats Superhydrophilic. Langmuir 2015, 31 (19), 5495-5503.

14. Shi, Q.; Ye, S.; Kristalyn, C.; Su, Y.; Jiang, Z.; Chen, Z. Probing Molecular-Level Surface Structures of Polyethersulfone/Pluronic F127 Blends Using Sum-Frequency Generation Vibrational Spectroscopy. Langmuir 2008, 24 (15), 7939-7946.

15. Öner, D.; McCarthy, T. J. Ultrahydrophobic Surfaces. Effects of Topography Length Scales on Wettability. Langmuir 2000, 16 (20), 7777-7782.

16. Callies, M.; Quere, D. On water repellency. Soft Matter 2005, 1 (1), 55-61.

17. Clarke, A.; Blake, T. D.; Carruthers, K.; Woodward, A. Spreading and Imbibition of Liquid Droplets on Porous Surfaces. Langmuir 2002, 18 (8), 2980-2984. 
18. Seveno, D.; Ledauphin, V.; Martic, G.; Voué, M.; De Coninck, J. Spreading Drop Dynamics on Porous Surfaces. Langmuir 2002, 18 (20), 7496-7502.

19. Hotaling, N. A.; Bharti, K.; Kriel, H.; Simon Jr, C. G. DiameterJ: A validated open source nanofiber diameter measurement tool. Biomaterials 2015, 61, 327-338.

20. Bico, J.; Tordeux, C.; Quéré, D. Rough wetting. EPL (Europhysics Letters) 2001, 55 (2), 214.

21. Ishino, C.; Reyssat, M.; Reyssat, E.; Okumura, K.; Quéré, D. Wicking within forests of micropillars. EPL (Europhysics Letters) 2007, 79 (5), 56005.

22. Kim, C. H.; Khil, M. S.; Kim, H. Y.; Lee, H. U.; Jahng, K. Y. An improved hydrophilicity via electrospinning for enhanced cell attachment and proliferation. Journal of Biomedical Materials Research Part B: Applied Biomaterials 2006, $78 B$ (2), 283-290.

23. Valiquette, D.; Pellerin, C. Miscible and Core-Sheath PS/PVME Fibers by Electrospinning. Macromolecules 2011, 44 (8), 2838-2843.

24. Dufficy, M. K.; Geiger, M. T.; Bonino, C. A.; Khan, S. A. Electrospun Ultrafine Fiber Composites Containing Fumed Silica: From Solution Rheology to Materials with Tunable Wetting. Langmuir 2015, 31 (45), 12455-12463.

25. Tsai, P.; Pacheco, S.; Pirat, C.; Lefferts, L.; Lohse, D. Drop Impact upon Micro- and Nanostructured Superhydrophobic Surfaces. Langmuir 2009, 25 (20), 12293-12298.

26. Reyssat, M.; Pépin, A.; Marty, F.; Chen, Y.; Quéré, D. Bouncing transitions on microtextured materials. EPL (Europhysics Letters) 2006, 74 (2), 306.

27. Alexandridis, P.; Alan Hatton, T. Poly(ethylene oxide) • poly(propylene oxide) • poly(ethylene oxide) block copolymer surfactants in aqueous solutions and at interfaces: thermodynamics, structure, dynamics, and modeling. Colloids and Surfaces A: Physicochemical and Engineering Aspects 1995, 96 (1-2), 1-46.

28. Range, K.; Feuillebois, F. Influence of Surface Roughness on Liquid Drop Impact. Journal of Colloid and Interface Science 1998, 203 (1), 16-30.

29. Sahu, R. P.; Sinha-Ray, S.; Yarin, A. L.; Pourdeyhimi, B. Drop impacts on electrospun nanofiber membranes. Soft Matter 2012, 8 (14), 3957-3970.

30. Lembach, A. N.; Tan, H.-B.; Roisman, I. V.; Gambaryan-Roisman, T.; Zhang, Y.;

Tropea, C.; Yarin, A. L. Drop Impact, Spreading, Splashing, and Penetration into Electrospun Nanofiber Mats. Langmuir 2010, 26 (12), 9516-9523.

31. Courbin, L.; Bird, J. C.; Reyssat, M.; Stone, H. A. Dynamics of wetting: from inertial spreading to viscous imbibition. Journal of Physics: Condensed Matter 2009, 21 (46), 464127.

32. Washburn, E. W. The Dynamics of Capillary Flow. Physical Review 1921, 17 (3), 273283.

33. Ferrero, F. Wettability measurements on plasma treated synthetic fabrics by capillary rise method. Polymer Testing 2003, 22 (5), 571-578.

34. Lowery, J. L.; Datta, N.; Rutledge, G. C. Effect of fiber diameter, pore size and seeding method on growth of human dermal fibroblasts in electrospun poly( $\varepsilon$-caprolactone) fibrous mats. Biomaterials 2010, 31 (3), 491-504.

35. Kabanov, A. V.; Batrakova, E. V.; Alakhov, V. Y. Pluronic ${ }^{\circledR}$ block copolymers as novel polymer therapeutics for drug and gene delivery. Journal of Controlled Release 2002, 82 (2-3), 189-212. 
Table of Contents Graphic

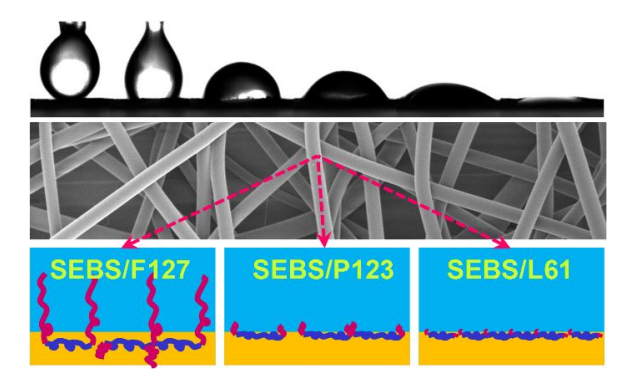

1

2

4

5

6

7

8

10

12

13

14

15

16

17

18

19

20

21

22

23

24

25

26

27

28

29

30

31

32

33

34

35

36

37

38

39

40

41

42

43

44

45

46

47

48

49

50

51

52

53

54

55

56

57

58

59

60 


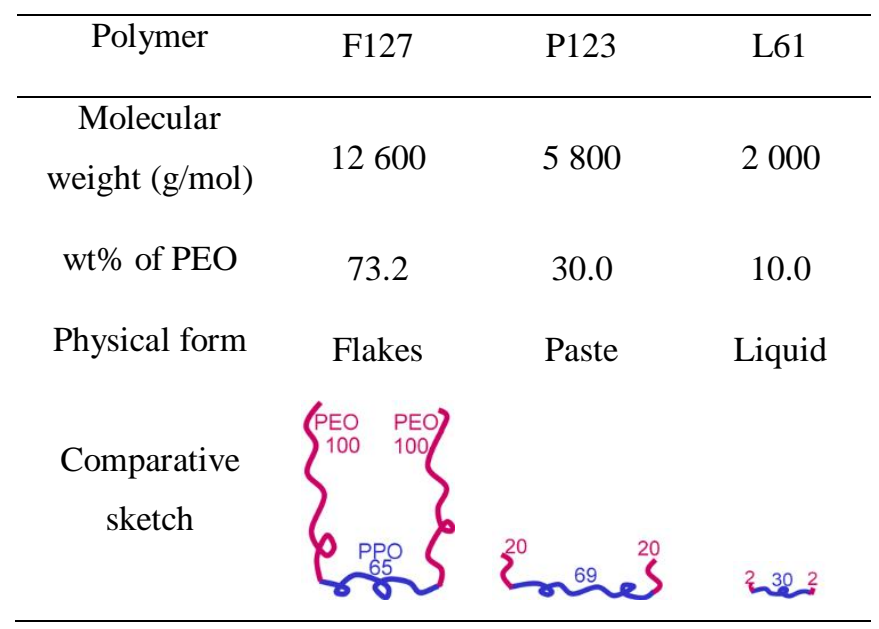




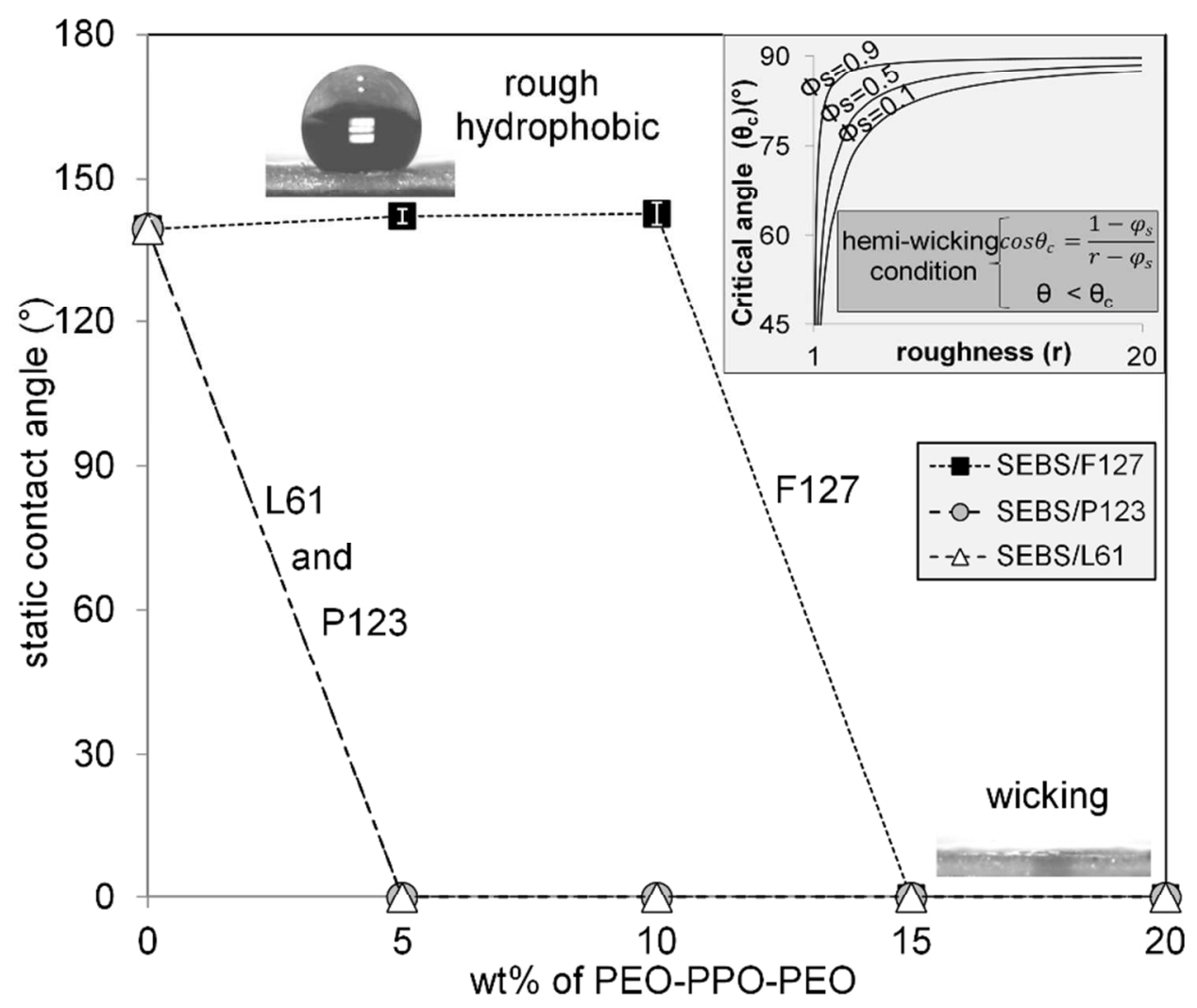

Figure 1 - Water contact angle results for all electrospun mats as a function of PEO-PPO-PEO content. The insert is a plot of the hemi-wicking condition ${ }^{20}$, the critical contact angle $\theta_{c}$ as a function of roughness $r$ for different values of solid/liquid interface fraction $\left(\varphi_{\mathrm{s}}\right)$. $80 \times 69 \mathrm{~mm}(300 \times 300 \mathrm{DPI})$ 
(a)

Figure 2 - (a) spreading and imbibition experiments methodology and results for the contact angle $\theta$ as a function of time; (b) drop impact images showing the last frame before impact as the first image and the total time for absorption as the final image for F127_20, P123_20 and L61_20 (top to bottom). $127 \times 85 \mathrm{~mm}(300 \times 300 \mathrm{DPI})$ 

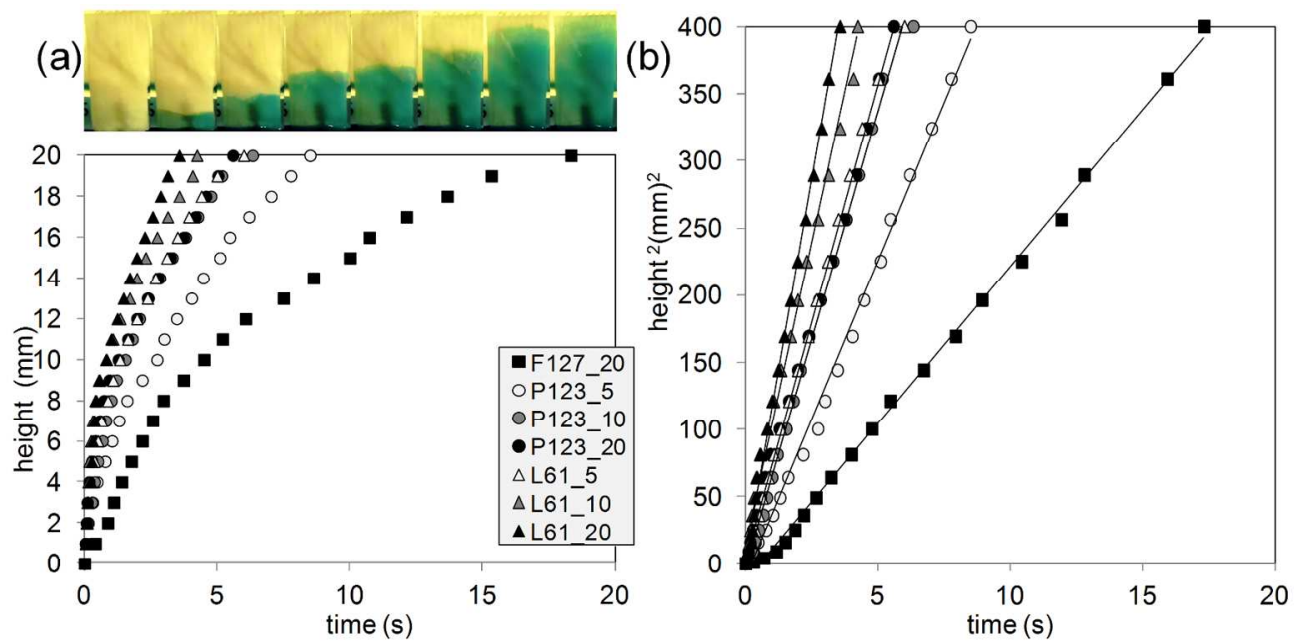

(c) 140 - D coefficient

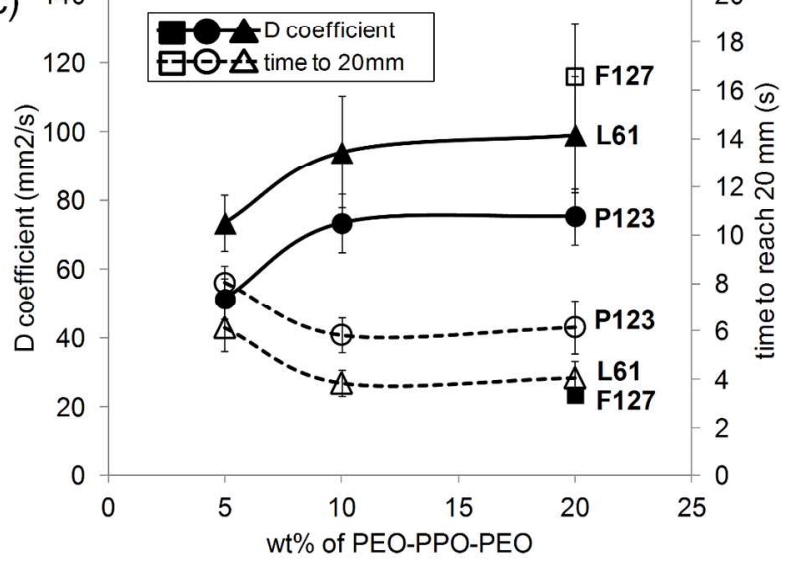

Figure 3 - Results for the wicking measurements: (a) example of the experiments pictures and the results for height as a function of time; (b) the square of height $\left(h^{2}\right)$ versus time; (c) Diffusion coefficient $D$ and total time to reach the maximum height as a function of PEO-PPO-PEO content. $150 \times 143 \mathrm{~mm}(300 \times 300 \mathrm{DPI})$ 

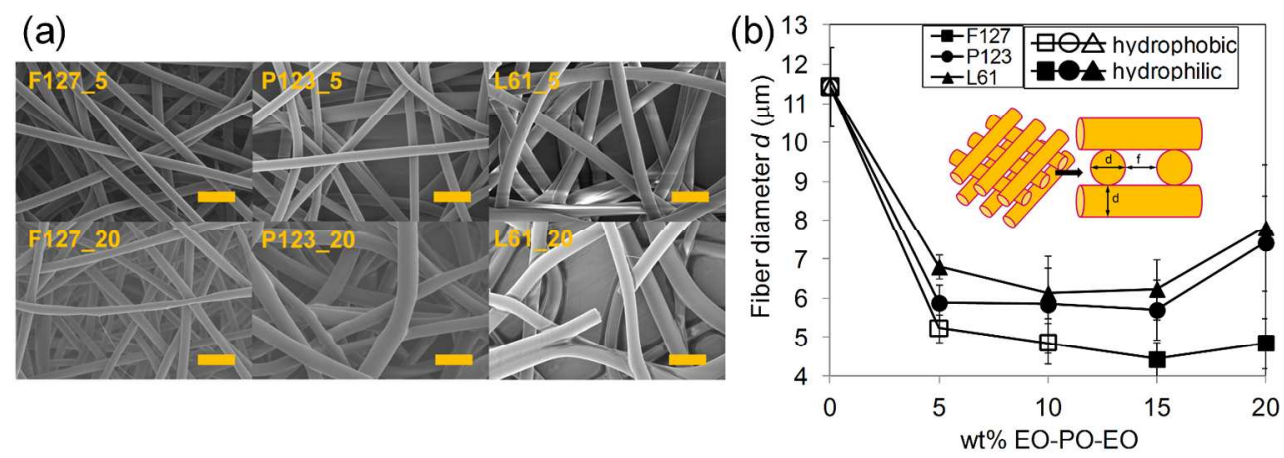

Figure 4 - (a) SEM micrographs of the samples containing 5 and 20 wt $\%$ of PEO-PPO-PEO (scale bar $=20$ $\mu \mathrm{m})$ and (b) the results of fiber diameter as a function of PEO-PPO-PEO content for all samples. $148 \times 52 \mathrm{~mm}(300 \times 300 \mathrm{DPI})$ 

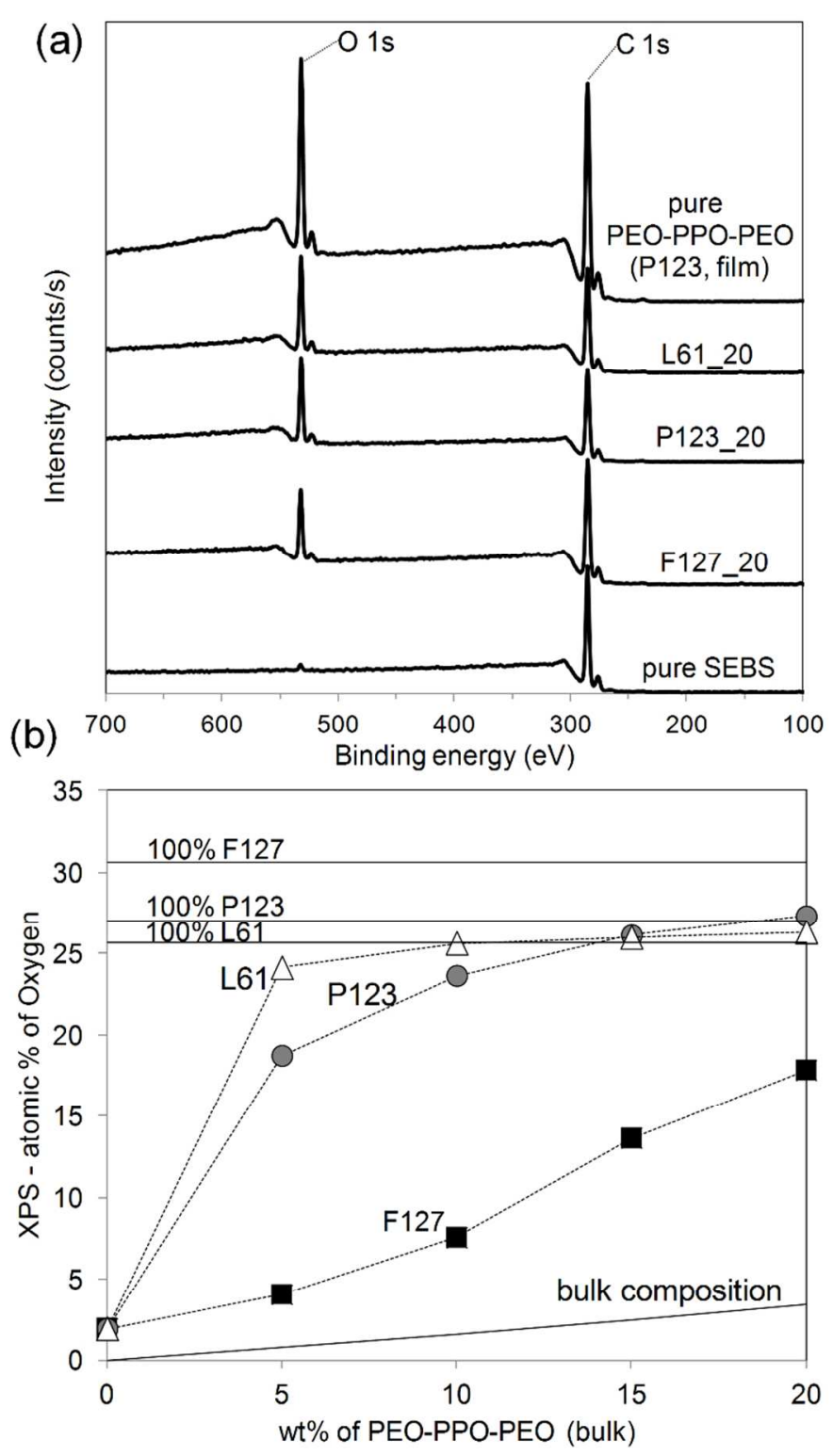

Figure 5 - (a) X-ray photoelectron spectroscopy (XPS) survey spectra for pure SEBS, F127_20, P123_20, L61_20 and pure PEO-PPO-PEO; (b) XPS results of the atomic percentage of oxygen as a function of blend bulk composition. The straight lines are theoretical values based on the chemical structure of each molecule. $70 \times 119 \mathrm{~mm}(300 \times 300 \mathrm{DPI})$ 


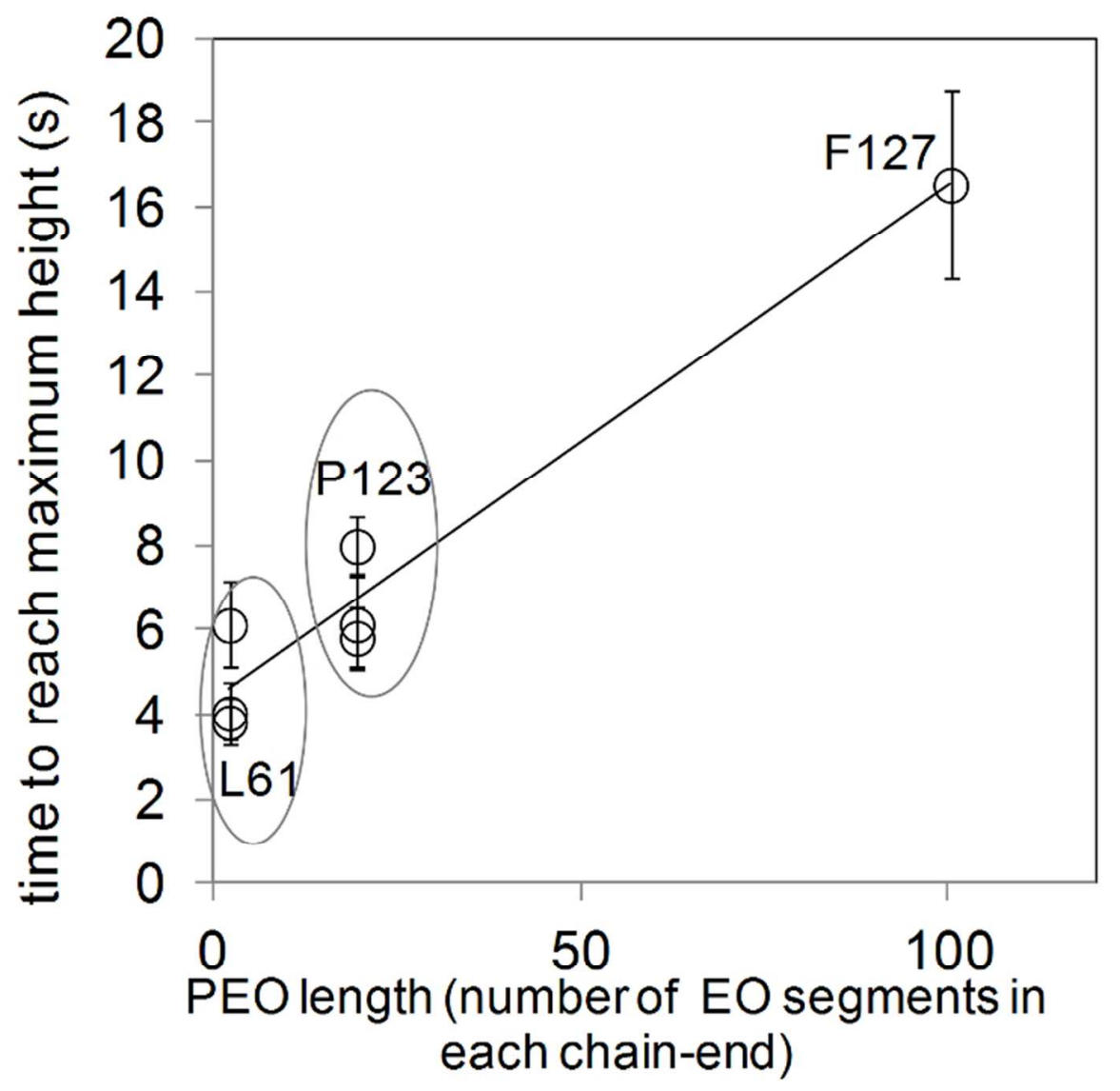

Figure 6 - Wicking results as a function of the number of EO segments in each side of the PEO-PPO-PEO molecules.

$69 \times 61 \mathrm{~mm}(300 \times 300$ DPI $)$ 


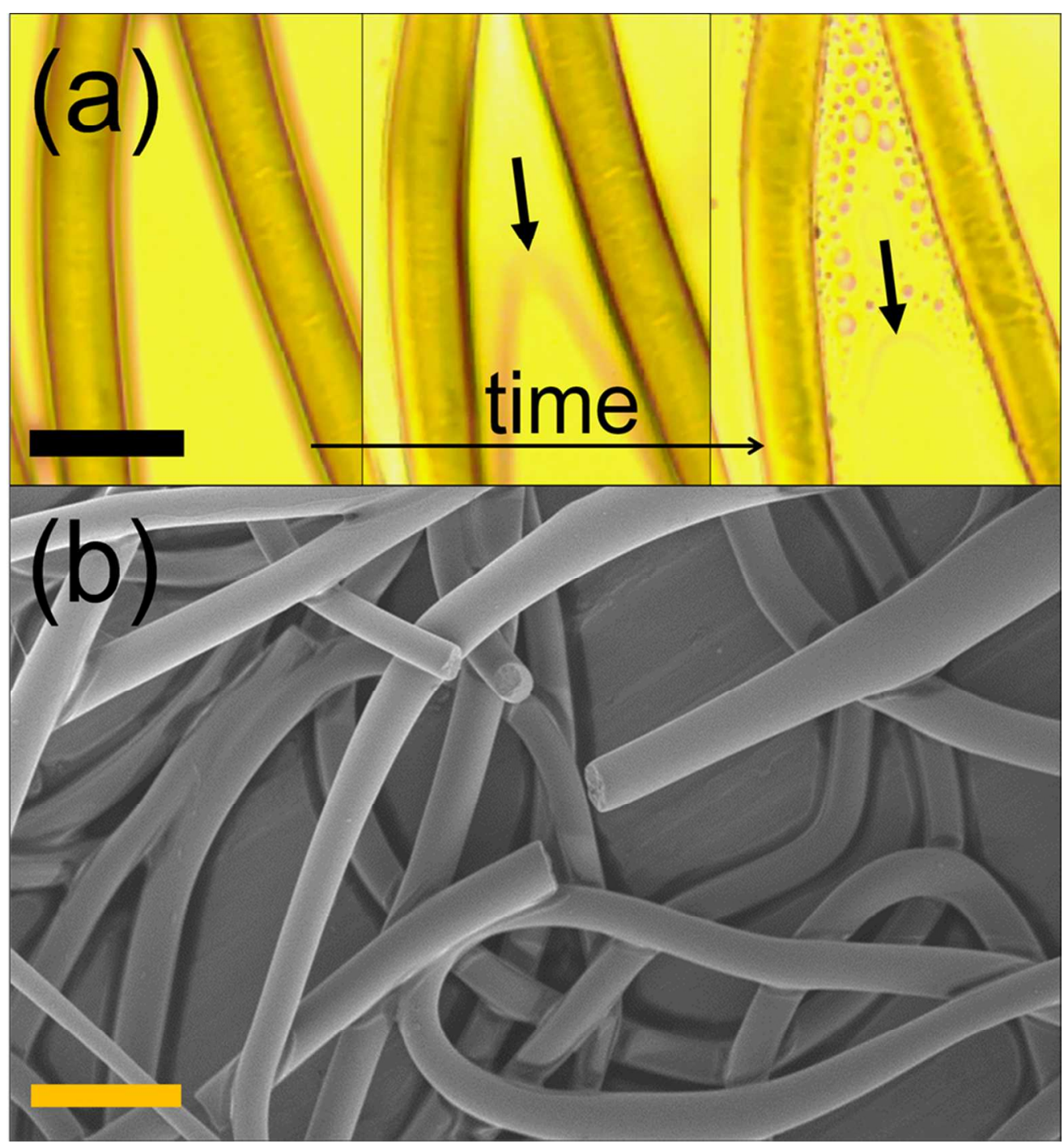

Figure 7 - L61_20 fibers: (a) L61 leaching observed by optical microscopy, in which the arrows indicate the water front advancing direction (scale bar = $10 \mu \mathrm{m}$ ); (b) SEM image of the same composition showing broken fibers (scale bar $=30 \mu \mathrm{m}$ ). $79 \times 85 \mathrm{~mm}(300 \times 300 \mathrm{DPI})$ 


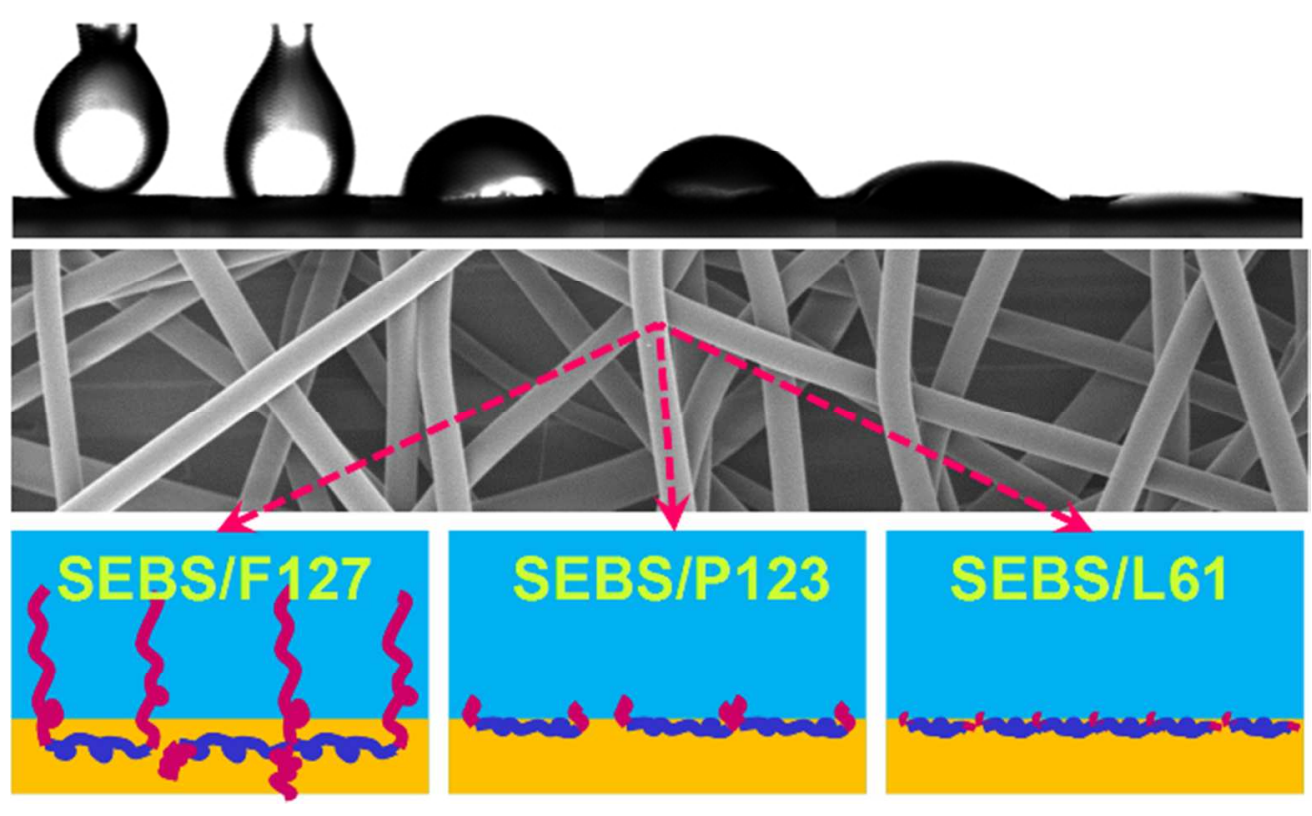

Table of contents graphic $58 \times 35 \mathrm{~mm}(300 \times 300 \mathrm{DPI})$ 